\title{
Sepsis and septic shock in France: incidences, outcomes and costs of care
}

Claire Dupuis ${ }^{1,2^{*}} \mathbb{B}$, Lila Bouadma ${ }^{2,3}$, Stéphane Ruckly², Anne Perozziello², Damien Van-Gysel ${ }^{4}$, Arthur Mageau², Bruno Mourvillier ${ }^{5}$, Etienne de Montmollin ${ }^{2,3}$, Sébastien Bailly ${ }^{6,7}$, Gregory Papin ${ }^{8}$, Fabrice Sinnah ${ }^{3}$,

Camille Vinclair ${ }^{9}$, Sonia Abid ${ }^{3}$, Romain Sonneville ${ }^{2,3}$ and Jean-François Timsit ${ }^{2,3}$

\begin{abstract}
Background: Sepsis is one of the leading causes of death worldwide. The associated incidence, mortality and trends do not differ greatly between documented reports. The purpose of this study was to provide an in-depth description of patients with sepsis and septic shock hospitalized in France from 2010 to 2015 and to explore the temporal trends of their clinical characteristics, costs and outcomes.
\end{abstract}

Methods: Retrospective cohort study of the French hospital administrative database in which organ failure therapies and severity scores are systematically registered. All patients admitted between 2010 and 2015 for sepsis and septic shock as defined by an ICD-10 code for infection, and for organ failure or the use of organ failure supplementation were included. Incidence, outcomes and trends were analyzed. Subgroup analyses based on several coding strategies and adjusted for severity scores were performed.

Results: A total of 737,147 patients with sepsis and 492,902 patients with septic shock were included. From 2010 to 2015, the incidence of sepsis and septic shock increased, respectively, from 206 to 243 and from 135 to 171 cases per 100,000 population. Case fatality remained at 34\% for sepsis, but decreased from 46 to $44 \%$ for septic shock.

Median hospital stay costs amounted to $€ 11,400$ (IQR: 5036; 24,364) for patients with sepsis and €16,439 (IQR: 7339; 29,360) for patients with septic shock.

After adjustment for case-mix and illness severity, the risk of death was stable for sepsis $(0.08 \%[-0.04 ; 0.20]$ per year), but decreased for sepsis patients admitted to the intensive care unit and for cases of septic shock $(-0.33 \%[-0.40$; - 0.27] per year).

Conclusions: Sepsis is common, frequently fatal and expensive to treat. Its incidence has increased. Case fatality has decreased in most severely affected patients, owing partly to general improvements in care.

Keywords: Sepsis, Septic shock, Epidemiology, Secular trends

\section{Background}

Sepsis is one of the leading causes of death worldwide and is a major public health issue [1-5]. The Intensive Care Over Nations (ICON) Audit [1] showed that sepsis accounts for $30 \%$ of reasons for intensive care unit (ICU)

\footnotetext{
*Correspondence: cdupuis1@chu-clermontferrand.fr

${ }^{1}$ Medical Intensive Care Unit, Gabriel Montpied University Hospital,

Clermont-Ferrand, France

Full list of author information is available at the end of the article
}

admission and is associated with a hospital mortality rate of $35 \%$. A recent review of 27 epidemiologic studies, mostly based on North American, Australian and North European administrative databases [2], showed an incidence rate of sepsis cases of 270 per 100,000 person-years (95\% CI, 176-412) and an in-hospital mortality rate of $26 \%$. However, previous results extracted from administrative databases were quite heterogeneous, mostly because of the differences in the International

\section{Springer Open}

(c) The Author(s) 2020. This article is licensed under a Creative Commons Attribution 4.0 International License, which permits use, sharing, adaptation, distribution and reproduction in any medium or format, as long as you give appropriate credit to the original author(s) and the source, provide a link to the Creative Commons licence, and indicate if changes were made. The images or other third party material in this article are included in the article's Creative Commons licence, unless indicated otherwise in a credit line to the material. If material is not included in the article's Creative Commons licence and your intended use is not permitted by statutory regulation or exceeds the permitted use, you will need to obtain permission directly from the copyright holder. To view a copy of this licence, visit http://creativeco mmons.org/licenses/by/4.0/. 
Classification of Diseases (ICD) coding strategies used to define sepsis [6, 7] (Additional file 1: Table S1).

In France, the medico-economic administrative hospital database called PMSI (French acronym for "Programme de Médicalisation des Systèmes d'Information") provides data on all hospital stays in France. Unlike other systems, the PMSI includes mandatory calculations of the Simplified Acute Physiology Score II (SAPS II) severity scores and daily monitoring of organ failure supplementation.

Our aim was to provide an up-to-date report on the epidemiology and management of sepsis and septic shock in France between 2010 and 2015, and to explore the temporal trends of their clinical characteristics, costs and outcomes.

\section{Methods}

\section{Study design and setting}

We analyzed all hospital stays in France from January 1, 2010 to December 31, 2015 of patients older than 18 years identified by codes corresponding to sepsis or septic shock.

\section{Data source}

The French healthcare system covers both public and private hospitals which provide healthcare to every resident in the country. Most French healthcare costs are covered by a public healthcare insurance scheme. Data on all hospital stays are thus recorded in the PMSI.

Demographic and clinical data were collected from the PMSI database including all discharge diagnoses (ICD-10 codes [International Classification of Diseases, Tenth Revision)]), daily records of medical procedures performed during hospital stays (CCAM codes [French acronyms for "Classification Commune des Actes Médicaux"]) including organ failure supplementation, date of discharge, length of stay(LOS), diagnosis-related groups (GHM [French acronym for "Groupe Homogène de Malades"]) to classify patients into subgroups according to medical procedures and discharge diagnoses, and finally SAPS II score in case of ICU admission. We estimated the direct cost of each hospital stay. Briefly, it is the sum of a global price defined by the main diagnosis of the hospital stay and severity of the disease and some supplements based on length of stay and special procedures performed during hospital stays such as renal replacement therapy. More details are given in the online daily supplement (Additional file 1: Fig. S1). The estimates of the yearly French total population were provided by the French National Institute for Statistics and Economic Studies, a publicly available database of census records for the entire country [8].

\section{Definitions}

Codes attributed during all hospital stays were considered. Among adults older than 18 years old, hospital stays for sepsis and septic shock were identified by ICD-10 and/or procedure codes according to explicit definitions using the direct codes for sepsis and septic shock (Fig. 1) [6, 7] or according to implicit definitions with an ICD-10 code for infection and a diagnostic code for organ failure for sepsis (or a diagnostic code for shock for septic shock) or a procedure code for the use of organ failure supplementation for sepsis (or of only vasopressor for septic shock). Several implicit definitions were compared depending on the infection codes (a wide definition including more than 1,000 codes, similar to that used by Fleischman [7], and a narrower definition only focusing on septicemia codes [9]), and on the definitions of organ failure (a. procedure codes or ICD-10 codes; b. ICD-10 codes; $c$. procedure codes) (Additional file 1: Tables S2, S3).

\section{Characteristics recorded}

A hospital stay was analyzed from admission to death or discharge, taking into account all potential transfers. For each hospital stay, the following data were obtained: demographics, hospital characteristics, reason for admission, readmissions, wards where the patients were admitted, patient comorbidities according to ICD10 Charlson score [10], severity of disease on admission (organ failures and SAPS II only for patients admitted to the ICU) and the characteristics of the sepsis (Additional file 1: Tables S2, S3). The direct costs of each hospital stay were estimated. ICU and hospital LOS, and outcomes including death and discharge home were recorded.

\section{Aim of the study}

The aim of our study was to explore the temporal trends in clinical characteristics, case-mix, costs and outcomes of septic and septic shock patients in France from 2010 to 2015 .

\section{Sensitivity and subgroup analyses}

Subgroup analyses were performed according to the definitions of sepsis and septic shock, but also among patients admitted to the ICU and those never admitted.

\section{Statistical analyses}

First, standard descriptive statistics were performed for the whole cohort and by year from 2010 to 2015 . Data were summarized as frequency and percentage for categorical variables, and median and interquartile for continuous variables. Second, the incidence and 


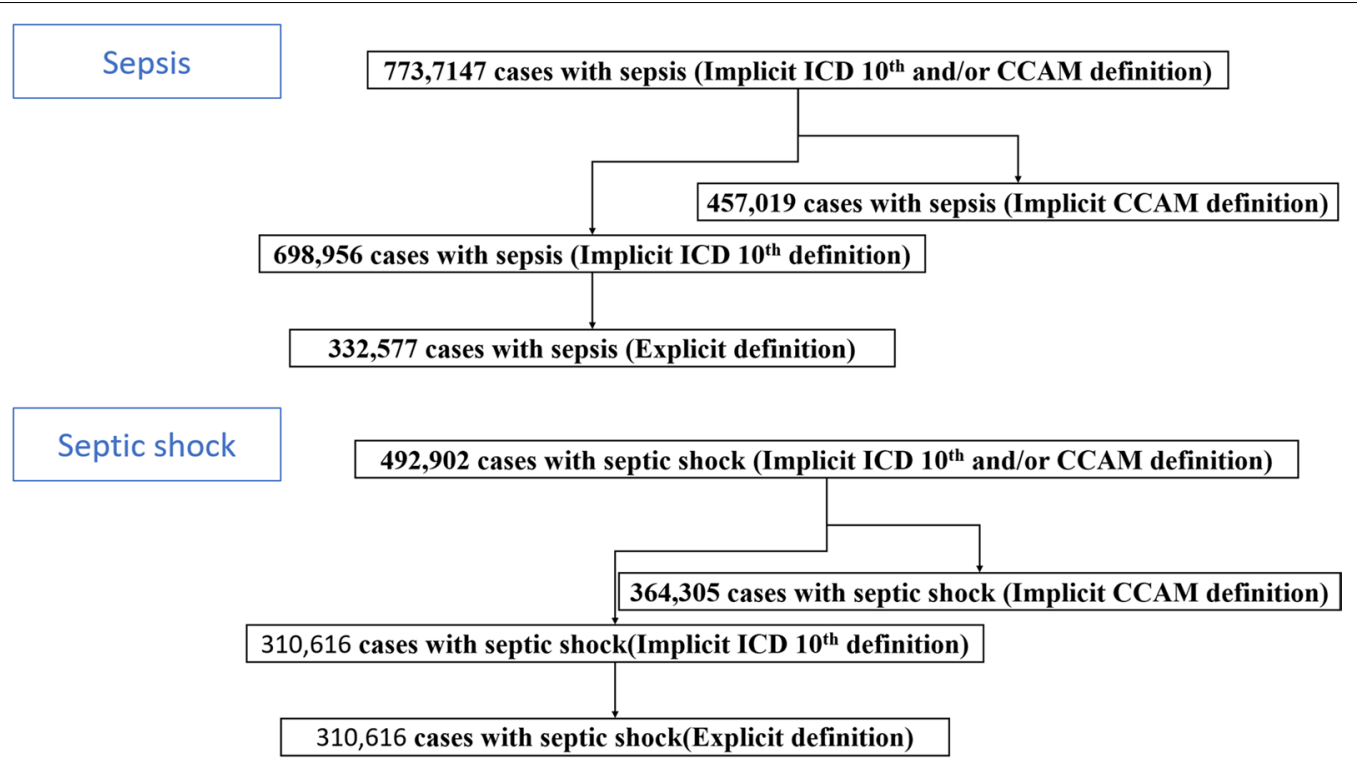

Fig. 1 ICD-10: International Statistical Classification of Diseases, 10th Edition. CCAM: "classification commune des actes médicaux". Implicit definition of sepsis: a code for infection using ICD-10 and a code for organ failure and/or a procedure code for the use of organ failure supplementation (using ICD-10 and/or CCAM). Explicit definition of sepsis: ICD-10 codes including R651 or R572 or R578 or R579. Implicit definition of septic shock: a code for infection using ICD-10 and a code for shock and/or a procedure code for the use of vasopressor (using ICD-10 and/or CCAM). Explicit definition of septic shock: ICD-10 codes including R572 or R578 or R579

hospital mortality rates were estimated from national population data expressing the results per 100,000 inhabitants. The in-hospital case-fatality rates (CFR) were calculated as the number of in-hospital deaths divided by the number of cases, expressed as percentages. The age-adjusted rates (incidence, mortality) were calculated by direct standardization based on the size of the population living in France in 2010 [7]. Age and CFR were calculated by direct standardization based on the 2010 data [7]. Third, the temporal trends of all the variables of interest were assessed. Cochran Armitage tests of trends and linear trend analyses to explore any changes from 2010 to 2015 were conducted. Fourth, multivariate hierarchical logistic regression analyses with a random center effect were performed to identify the factors associated with death. The variables were selected by univariate analyses with a threshold of 0.1 , after which a backward selection was performed in the multivariate analyses. The tested covariates are listed in the supplementary data. Of these covariates, the SAPS II score was only assessed in the subgroup of the ICU-admitted patients. The covariates 'Year of admission' and 'Readmissions during the year following the last admission' were forced into each model. All these analyses were performed in each of the predetermined subgroups. P-values less than 0.05 were considered significant. Fifth, from the adjusted odds ratio and the prevalence of death in the whole cohort of patients with sepsis or septic shock, we determined the relative risk of death of each year relative to that of 2010 [11]. Finally, the adjusted increased risk of death per year was derived from the slope of the regression line through the adjusted relative risk of death per year. Analyses were performed solely of characteristics and cases identified according to our coding strategies. Data were analyzed with $\mathrm{SAS}^{\circledR}$ (Version 9.4; SAS Institute, Cary, NC, USA) and R (Version 3.4.0; R Core Team, Wien, Austria).

\section{Ethical aspects}

In accordance with the French regulatory system regarding personal and medical data and after agreement of the French data protection authority (CNIL), our institution was allowed to access the PMSI database. We only had access to patients diagnosed with sepsis or septic shock according to our definition, and to pseudonymized data.

\section{Results \\ Incidence}

From 2010 to 2015, a total of 737,147 sepsis hospital stays from 1431 hospitals were recorded, with an implicit definition based on ICD-10 and/or CCAM coding, including 332,577 cases with an explicit definition, 519,049 cases admitted to the CU, and 141,669 cases with a code for septicemia (Fig. 1, Additional file 1: Table S4). The standardized incidence of sepsis defined implicitly increased 

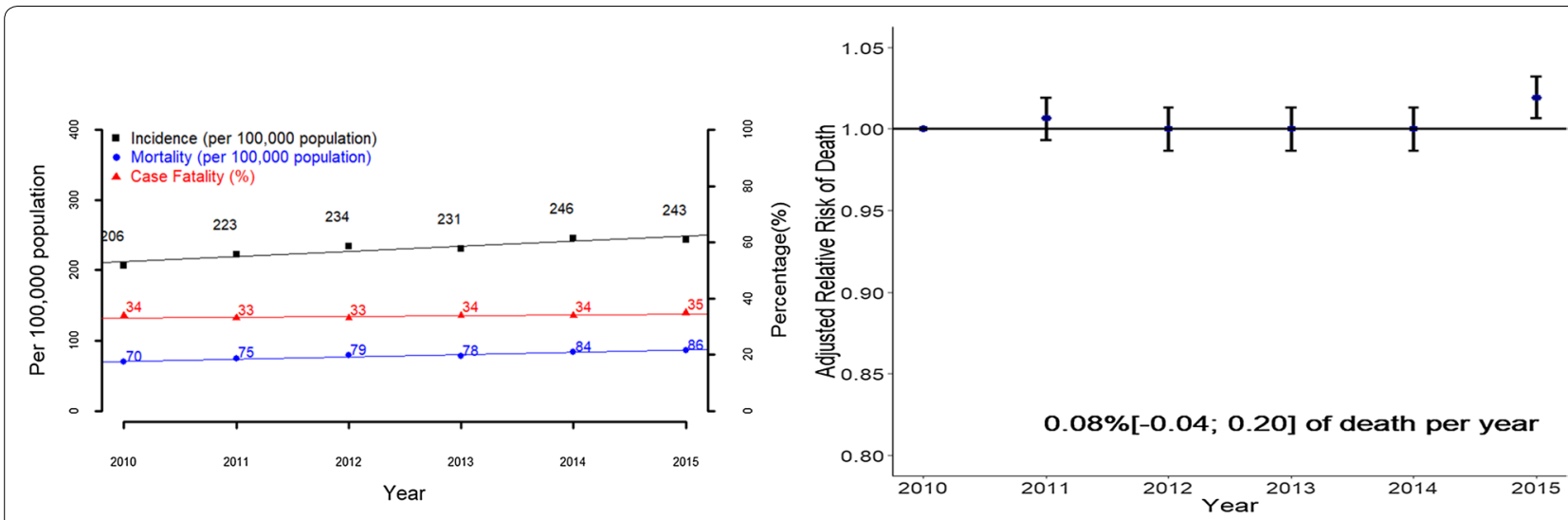

Fig. 2. Incidence, mortality, case fatality from 2010 to 2015 in the whole cohort of patients with sepsis (a) and adjusted relative risk of hospital death rate from 2010 to 2015, in the whole cohort of patients with sepsis (b). The adjusted relative risk of hospital death was based on the adjusted odd ratio of death obtained by a multivariate hierarchical logistic regression analysis with a random center effect taking into account all the associated factors of hospital death (Additional file 1: Table S11)

significantly in France from 206 per 100,000 inhabitants in 2010 to 243 per 100,000 inhabitants in 2015 (Fig. 2, Table 1). Similar trends were observed with regard to sepsis implicitly defined by the ICD-10 code and CCAM codes or explicitly defined, and among patients admitted to the ICU and those not admitted but not in the subgroup of patients with septicemia (Additional file 1: Fig S2, Tables S5-S7).

Similarly, from 2010 to 2015, 492,902 hospital stays due to septic shock with an implicit definition, including 310,616 with an explicit definition, 421,026 admitted to ICU and 113,722 with septicemia were included (Fig. 1). The standardized incidence of septic shock increased significantly from 135 to 171 per 100,000 inhabitants in France from 2010 to 2015 (Fig. 3, Table 2). Similar trends were observed regardless of the septic shock definition used and among patients admitted and not admitted to the ICU, but not in the subgroup of patients with septicemia (Additional file 1: Fig S3, Tables S8-S10).

\section{LOS and costs of care}

The median hospital and ICU LOS of patients with sepsis were, respectively, 17 days (IQR: $7 ; 34$ ) and 8 days (IQR: $3 ; 17$ ) and the cost of the median hospital stay cost amounted to $€ 11,400$ (IQR: 5036; 24,364). Hospital and ICU LOS decreased significantly over time, but not the cost of care (Table 1). Septic patients not admitted to the ICU were different from those admitted: they were older (77 years $[64 ; 85]$ ), had more dementia $(9 \%)$, were more often admitted to the emergency department (32\%), were less severely ill and had a shorter hospital LOS and lower cost of care (Additional file 1: Tables S6, S7).

The median hospital and ICU LOS of septic shock patients was, respectively, 20 days (IQR: 8 ; 39$)$ and 8 days
(IQR: $3 ; 18$ ) and the median hospital stay costs amounted to $€ 16,439$ (IQR: $7339 ; 29,360$ ). The hospital and ICU LOS decreased significantly over time, as did the associated cost of care (Table 2). Similar results were found in the subgroups of patients admitted to the ICU and those included with explicit definitions. Patients with septicemia tended to be more severely ill, with a longer ICU and hospital LOS that increased significantly over time. Finally, septic shock patients not admitted to the ICU were different from those admitted to ICU: they were older (77 years $[64 ; 85])$, had more cancer $(24 \%)$ and dementia (10\%), were more often admitted to the emergency department (40\%), and had a shorter hospital LOS and lower cost of care, possibly owing to pre-mortem misdiagnosis or early limitation of care (Additional file 1 : Tables S8-S10).

\section{Hospital mortality and hospital case fatalities}

The standardized mortality rate in France for sepsis implicitly defined increased significantly from 70 to 86 deaths per 100,000 inhabitants from 2010 to 2015, and from 62 to 75 deaths per 100,000 inhabitants for patients with septic shock implicitly defined. Similar trends were observed regardless of the sepsis or septic shock definitions used. However, no temporal trends were observed for patients with septicemia. CFR remained quite stable around $34 \%$ over time for sepsis with an implicit definition, but decreased from 50 to $48 \%$ from 2010 to 2015 for sepsis with an explicit definition and for patients with septicemia. CFR increased significantly from 24 to $32 \%$ for septic patients not admitted to the ICU. CFR for septic shock using an implicit definition decreased significantly from 46 to $44 \%$ from 2010 to 2015, but remained quite stable, around $51 \%$, when an explicit definition was 
Table 1 Main characteristics of the included sepsis hospital stays in France between 2010 and 2015 and their associated temporal trends

\begin{tabular}{|c|c|c|c|c|c|c|c|c|}
\hline $\begin{array}{l}\text { Sepsis } \\
\text { Implicit definition ICD 10th } \\
\text { or CCAM }\end{array}$ & All & 2010 & 2011 & 2012 & 2013 & 2014 & 2015 & Trends $^{a}$ \\
\hline Cases & 737,147 & 105,733 & 116,139 & 123,792 & 123,950 & 133,651 & 133,882 & \\
\hline $\begin{array}{l}\text { Incidence per } 100.000 \text { (age- } \\
\text { standardized) }\end{array}$ & & 206 & 223 & 234 & 231 & 246 & 243 & $\nearrow$ \\
\hline $\begin{array}{l}\text { Deaths per } 100.000 \text { (age-stand- } \\
\text { ardized) }\end{array}$ & & 70 & 75 & 79 & 78 & 84 & 86 & $\nearrow$ \\
\hline Case fatality (age standardized) & & 34 & 33 & 33 & 34 & 34 & 35 & $=$ \\
\hline \multicolumn{9}{|l|}{ Hospital stay characteristics } \\
\hline \multicolumn{9}{|l|}{ Services of admission } \\
\hline Intensive care unit & $388,057(52.6)$ & $56,314(53.3)$ & $60,150(51.8)$ & $63,662(51.4)$ & $64,436(52)$ & $70,743(52.9)$ & $72,752(54.3)$ & $\nearrow$ \\
\hline Intermediate care facilities & $198,626(26.9)$ & $24,112(22.8)$ & $28,671(24.7)$ & $32,556(26.3)$ & $34,917(28.2)$ & $38,780(29)$ & $39,590(29.6)$ & $\nearrow$ \\
\hline \multicolumn{9}{|l|}{ Characteristics of the patients } \\
\hline \multicolumn{9}{|l|}{ Baseline characteristics } \\
\hline Age in years, median (IQR) & $71[59 ; 81]$ & $70[58 ; 80]$ & $71[58 ; 80]$ & $71[59 ; 81]$ & $71[59 ; 81]$ & $71[60 ; 81]$ & $71[60 ; 81]$ & $\nearrow$ \\
\hline Gender (female) & $287,652(39)$ & $41,353(39.1)$ & $45,511(39.2)$ & $48,465(39.2)$ & $48,144(38.8)$ & $52,033(38.9)$ & $52,146(38.9)$ & $=$ \\
\hline \multicolumn{9}{|l|}{ Comorbidities } \\
\hline Myocardial infarction & $134,179(18.2)$ & $19,209(18.2)$ & $20,933(18)$ & $22,639(18.3)$ & $22,539(18.2)$ & $24,538(18.4)$ & $24,321(18.2)$ & $=$ \\
\hline Congestive heart failure & $222,310(30.2)$ & $30,211(28.6)$ & $33,946(29.2)$ & $37,440(30.2)$ & $37,837(30.5)$ & $41,556(31.1)$ & $41,320(30.9)$ & $\nearrow$ \\
\hline Dementia & $36,808(5)$ & $5209(4.9)$ & $5943(5.1)$ & $6416(5.2)$ & $6071(4.9)$ & $6722(5)$ & $6447(4.8)$ & $\searrow$ \\
\hline Chronic pulmonary disease & $135,443(18.4)$ & $18,608(17.6)$ & $20,608(17.7)$ & $22,724(18.4)$ & $22,514(18.2)$ & $25,356(19)$ & $25,633(19.1)$ & $\nearrow$ \\
\hline $\begin{array}{l}\text { Diabetes without chronic } \\
\text { complication }\end{array}$ & $127,251(17.3)$ & $17,831(16.9)$ & $19,051(16.4)$ & $21,231(17.2)$ & $21,563(17.4)$ & $24,185(18.1)$ & $23,390(17.5)$ & $\nearrow$ \\
\hline $\begin{array}{l}\text { Diabetes with chronic compli- } \\
\text { cations }\end{array}$ & $73,562(10)$ & $11,029(10.4)$ & $11,591(10)$ & $12,682(10.2)$ & $11,938(9.6)$ & $13,432(10.1)$ & $12,890(9.6)$ & $\searrow$ \\
\hline Renal disease & $105,153(14.3)$ & $12,925(12.2)$ & $15,158(13.1)$ & $17,544(14.2)$ & $18,002(14.5)$ & $20,969(15.7)$ & $20,555(15.4)$ & $\nearrow$ \\
\hline Any malignancy & $161,307(21.9)$ & $22,040(20.8)$ & $24,530(21.1)$ & $26,863(21.7)$ & $27,548(22.2)$ & $30,434(22.8)$ & $29,892(22.3)$ & $\nearrow$ \\
\hline $\begin{array}{l}\text { Moderate or severe liver } \\
\text { disease }\end{array}$ & $56,528(7.7)$ & $8224(7.8)$ & $9061(7.8)$ & $9643(7.8)$ & $9735(7.9)$ & $10,132(7.6)$ & $9733(7.3)$ & $\searrow$ \\
\hline Metastatic solid tumor & $52,933(7.2)$ & $6420(6.1)$ & $7616(6.6)$ & $8558(6.9)$ & $9128(7.4)$ & $10,555(7.9)$ & $10,656(8)$ & $\nearrow$ \\
\hline Charlson score, median (IQR) & $2[1 ; 4]$ & $2[1 ; 4]$ & $2[1 ; 4]$ & $2[1 ; 4]$ & $2[1 ; 4]$ & $2[1 ; 5]$ & $2[1 ; 5]$ & $\nearrow$ \\
\hline \multicolumn{9}{|l|}{ Illness severity } \\
\hline Cardio-vascular organ failure & $514,797(69.8)$ & $70,002(66.2)$ & $79,693(68.6)$ & $85,081(68.7)$ & $86,258(69.6)$ & $95,238(71.3)$ & $98,525(73.6)$ & $\nearrow$ \\
\hline Neurological organ failure & $184,188(25)$ & $22,442(21.2)$ & $26,932(23.2)$ & $30,623(24.7)$ & $31,451(25.4)$ & $35,160(26.3)$ & $37,580(28.1)$ & $\nearrow$ \\
\hline Renal organ failure & $294,273(39.9)$ & $40,331(38.1)$ & $44,465(38.3)$ & $48,585(39.2)$ & $50,323(40.6)$ & $54,827(41)$ & $55,742(41.6)$ & $\nearrow$ \\
\hline Respiratory organ failure & $297,664(40.4)$ & $42,835(40.5)$ & $46,876(40.4)$ & $49,722(40.2)$ & $50,134(40.4)$ & $53,558(40.1)$ & $54,539(40.7)$ & $=$ \\
\hline $\begin{array}{l}\text { Number of organ failure, } \\
\text { median (IQR) }\end{array}$ & $3[2 ; 4]$ & $3[2 ; 4]$ & $3[2 ; 4]$ & $3[2 ; 4]$ & $3[2 ; 4]$ & $3[2 ; 4]$ & $3[2 ; 4]$ & $\nearrow$ \\
\hline $\begin{array}{l}\text { SAPS II score, median (IQR) } \\
\quad(\text { miss }=241,497 x)\end{array}$ & $48[35 ; 64]$ & $48[35 ; 64]$ & $48[35 ; 64]$ & $48[35 ; 64]$ & $48[35 ; 64]$ & $48[35 ; 64]$ & $49[36 ; 65]$ & $\nearrow$ \\
\hline \multicolumn{9}{|l|}{ Outcomes } \\
\hline $\begin{array}{l}\text { Hospital LOS(days) (median } \\
{[\text { [QR]) }}\end{array}$ & $17[7 ; 34]$ & $17[7 ; 35]$ & $17[7 ; 34]$ & $17[7 ; 34]$ & $17[7 ; 34]$ & $17[8 ; 34]$ & $17[7 ; 33]$ & $\searrow$ \\
\hline $\begin{array}{l}\text { ICU LOS(days) (median [IQR]) } \\
\quad \text { (missing }=332,463)\end{array}$ & $8[3 ; 17]$ & $8[3 ; 19]$ & $8[3 ; 18]$ & $8[3 ; 17]$ & $8[3 ; 17]$ & $7[3 ; 17]$ & $7[3 ; 16]$ & $\searrow$ \\
\hline Discharge to home & $391,409(53.1)$ & $55,590(52.6)$ & $62,161(53.5)$ & $66,413(53.6)$ & $66,035(53.3)$ & $71,825(53.7)$ & $69,385(51.8)$ & $\searrow$ \\
\hline Hospital mortality & $254,013(34.5)$ & $36,206(34.2)$ & $39,505(34)$ & $42,111(34)$ & $42,415(34.2)$ & $45,797(34.3)$ & $47,979(35.8)$ & $\nearrow$ \\
\hline Cost $(€)$, median (IQR) & $\begin{array}{l}11,400 \\
{[5037 ; 24363]}\end{array}$ & $\begin{array}{l}11,705.9 \\
{[5088 ; 25364]}\end{array}$ & $\begin{array}{l}10,991.2 \\
{[4778 ; 24209]}\end{array}$ & $\begin{array}{l}10,856.1 \\
{[4789 ; 23810]}\end{array}$ & $\begin{array}{l}11,314 \\
{[4938 ; 24378]}\end{array}$ & $\begin{array}{l}11,648.3 \\
{[5164 ; 24362]}\end{array}$ & $\begin{array}{l}11,847.3 \\
{[5218 ; 24192]}\end{array}$ & $=$ \\
\hline
\end{tabular}

${ }^{a}$ Test of trend or linear regression for values from 2010 to 2015 ; $\nearrow$ a significant increase is observed with a $p$ value $\langle 0.05$; $\backslash$ a significant decrease is observed with a p value $<0.05 ;^{\prime}=$ 'no significant trend is observed; a Missing values of 241,497 because SAPS II score was only recorded in case of ICU stay; SAPS II: Simplified Acute Physiology Score II; LOS: length of stay; ICU: intensive care unit 

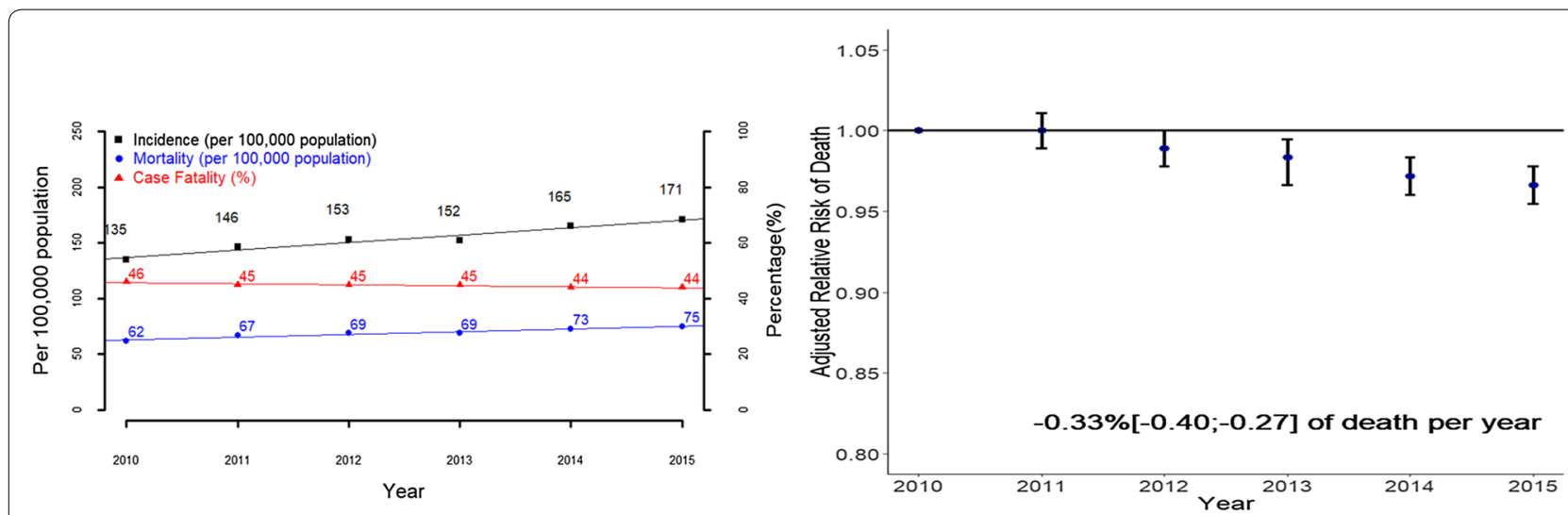

Fig. 3. Incidence, mortality, case fatality from 2010 to 2015 in the whole cohort of patients with septic shock (a) and adjusted relative risk of hospital death rate from 2010 to 2015, in the whole cohort of patients with septic shock (b). The adjusted relative risk of hospital death was based on the adjusted odd ratio of death obtained by a multivariate hierarchical logistic regression analysis with a random center effect taking into account all the associated factors of hospital death (Additional file 1: Table S11)

used. The CFR of septic shock patients with septicemia decreased significantly from 47 to $42 \%$ while that of septic shock patients not admitted to the ICU increased significantly, from 59 to $64 \%$ (Figs. 2, 3, Tables 1, 2, Additional file 1: Tables S2, S3, S5-S7). The adjusted risk of death decreased significantly independently over time by $-0.33 \%$ per year (IQR: $-0.40 ;-0.27$ ) for patients with septic shock, but not for those with sepsis $(0.08 \%$ [ -0.04 ; 0.20] of deaths per year) (Figs. 2, 3, Additional file 1: Table S11).

\section{Discussion}

This in-depth evaluation of sepsis and septic shock in France from 2010 to 2015 using information from the French national hospital administrative database that records all hospital stays showed an increased incidence of sepsis and septic shock and a decrease in the associated risk of death limited to patients with septic shock. These results should be interpreted in light of our subgroup analyses and the current literature and deserve a few comments.

First, we found an increase in the incidence of sepsis and septic shock in the whole cohort and most of our subgroups. Several studies focusing on sepsis (Additional file 1: Table S1) [7, 9, 12-21] also reported an increased incidence. For instance, Fleischmann-Struzek et al. [7] reported an incidence of sepsis that increased from 108 per 100,000 population in 2010 to 158 in 2015 . As neither the identification codes nor the reimbursement strategies were modified from 2010 to 2015 in France, the increased incidence of sepsis or septic shock could have been related to an actual increase in the disease incidence due to greater risk factors for sepsis such as the ageing of the population, the increasing burden of comorbidities or the increasing rate of resistances to antibiotics. However, we believe that much of the increase could also be secondary to better identification and coding [22]. It is unfortunately impossible to directly determine how many patients were captured due to better identification. The solution might be to work on detailed clinical data extracted from the electronic health record systems of hospitals [22]. However, these data are not yet available for all hospital stays in France. Nevertheless, it is important to underline that the incidence of sepsis or septic shock due to septicemia has remained fairly stable over time, which indirectly supports a global increase in recognition of other sepsis. The recognition of other sepsis than septicemia could be related to the improvement in the diagnosis of sepsis thanks to successive surviving sepsis campaigns [3, 23], to an improved identification of the pathogens involved or to the rise in electronic medical records and hospital coding systems, which has led to the inclusion of more patients with perhaps less severe septic shock [18, 24, 25].

Septic shock, with a death rate of $45 \%$, is associated with a high risk of mortality. We observed a decrease in the adjusted risk of death by $-0.33 \%$ (IQR: $-0.4 ;-0.27$ ) per year. This decrease was also found in patients with most severe form of sepsis, i.e., those admitted to the ICU or with bacteremia. Those varying results prompt several remarks. First, to date most studies have reported a decrease in the risk of death over time, from $0.6 \%$ per year to $17 \%$ per year $[7,9,12-21]$. For instance, Kadri et al. [24] reported similar results for septic shock patients, with a decrease in the death rate of around $1.22 \%$ per year, from $48.3 \%$ in 2005 to $39.3 \%$ in 2014 . Similar results were also observed among patients with sepsis [26]. Our results, however, were the first to be obtained after adjustment, and compared to those from other countries 
Table 2 Main characteristics of the included septic shock hospital stays in France between 2010 and 2015 and their associated temporal trends

\begin{tabular}{|c|c|c|c|c|c|c|c|c|}
\hline $\begin{array}{l}\text { Septic shock } \\
\text { Implicit definition } \\
\text { ICD 10th or CCAM }\end{array}$ & All & 2010 & 2011 & 2012 & 2013 & 2014 & 2015 & Trends $^{a}$ \\
\hline Cases & 492,902 & 69,466 & 76,350 & 81,107 & 81,886 & 89,934 & 94,159 & \\
\hline $\begin{array}{l}\text { Incidence per } 100.000 \text { (age- } \\
\text { standardized) }\end{array}$ & & 135 & 146 & 153 & 152 & 165 & 171 & $\nearrow$ \\
\hline $\begin{array}{l}\text { Deaths per } 100.000 \text { (age-stand- } \\
\text { ardized) }\end{array}$ & & 62 & 67 & 69 & 69 & 73 & 75 & $\nearrow$ \\
\hline Case fatality (age standardized) & & 46 & 45 & 45 & 45 & 44 & 44 & $\searrow$ \\
\hline \multicolumn{9}{|l|}{ Hospital stay characteristics } \\
\hline \multicolumn{9}{|l|}{ Services of admission } \\
\hline Intensive care unit & $353,190(71.7)$ & $50,369(72.5)$ & $54,181(71)$ & $57,553(71)$ & $58,678(71.7)$ & $64,696(71.9)$ & $67,713(71.9)$ & $=$ \\
\hline Intermediate care facilities & $151,357(30.7)$ & $17,917(25.8)$ & $21,415(28)$ & $24,475(30.2)$ & $26,486(32.3)$ & $29,721(33)$ & $31,343(33.3)$ & $\nearrow$ \\
\hline \multicolumn{9}{|l|}{ Characteristics of the patients } \\
\hline \multicolumn{9}{|l|}{ Baseline characteristics } \\
\hline Age in years, median (IQR) & $70[59 ; 80]$ & $70[58 ; 79]$ & $70[58 ; 80]$ & $70[59 ; 80]$ & $70[59 ; 80]$ & $70[59 ; 80]$ & $70[60 ; 80]$ & $\nearrow$ \\
\hline Gender (female) & $190,941(38.7)$ & $27,069(39)$ & $29,513(38.7)$ & $31,535(38.9)$ & $31,811(38.8)$ & $34,677(38.6)$ & $36,336(38.6)$ & $=$ \\
\hline \multicolumn{9}{|l|}{ Comorbidities } \\
\hline Myocardial infarction & $90,838(18.4)$ & $12,922(18.6)$ & $13,913(18.2)$ & $15,084(18.6)$ & $15,111(18.5)$ & $16,656(18.5)$ & $17,152(18.2)$ & $=$ \\
\hline Congestive heart failure & $147,098(29.8)$ & $19,920(28.7)$ & $22,285(29.2)$ & $24,281(29.9)$ & $24,767(30.2)$ & $27,548(30.6)$ & $28,297(30.1)$ & $\nearrow$ \\
\hline Dementia & $21,630(4.4)$ & $3090(4.4)$ & $3466(4.5)$ & $3631(4.5)$ & $3541(4.3)$ & $3911(4.3)$ & $3991(4.2)$ & $=$ \\
\hline Chronic pulmonary disease & $80,759(16.4)$ & $10,835(15.6)$ & $12,109(15.9)$ & $13,237(16.3)$ & $13,073(16)$ & $15,206(16.9)$ & $16,299(17.3)$ & $\nearrow$ \\
\hline $\begin{array}{l}\text { Diabetes without chronic } \\
\text { complication }\end{array}$ & $81,220(16.5)$ & $11,171(16.1)$ & $11,832(15.5)$ & $13,319(16.4)$ & $13,739(16.8)$ & $15,467(17.2)$ & $15,692(16.7)$ & $\nearrow$ \\
\hline $\begin{array}{l}\text { Diabetes with chronic compli- } \\
\text { cations }\end{array}$ & $46,219(9.4)$ & $6735(9.7)$ & $7175(9.4)$ & $7762(9.6)$ & $7490(9.1)$ & $8519(9.5)$ & $8538(9.1)$ & $\searrow$ \\
\hline Renal disease & $61,383(12.5)$ & $7610(11)$ & $8875(11.6)$ & $10,003(12.3)$ & $10,266(12.5)$ & $12,231(13.6)$ & $12,398(13.2)$ & $\nearrow$ \\
\hline Any malignancy & $111,501(22.6)$ & $15,377(22.1)$ & $17,038(22.3)$ & $18,309(22.6)$ & $18,709(22.8)$ & $20,778(23.1)$ & $21,290(22.6)$ & $\nearrow$ \\
\hline $\begin{array}{l}\text { Moderate or severe liver } \\
\text { disease }\end{array}$ & $36,692(7.4)$ & $5306(7.6)$ & $5706(7.5)$ & $6115(7.5)$ & $6187(7.6)$ & $6559(7.3)$ & $6819(7.2)$ & $\searrow$ \\
\hline Metastatic solid tumor & $37,339(7.6)$ & $4734(6.8)$ & $5516(7.2)$ & $6033(7.4)$ & $6311(7.7)$ & $7271(8.1)$ & $7474(7.9)$ & $\nearrow$ \\
\hline Charlson score, median (IQR) & $2[1 ; 4]$ & $2[1 ; 4]$ & $2[1 ; 4]$ & $2[1 ; 4]$ & $2[1 ; 4]$ & $2[1 ; 4]$ & $2[1 ; 4]$ & $\nearrow$ \\
\hline \multicolumn{9}{|l|}{ IIIness severity } \\
\hline Neurological organ failure & $132,587(26.9)$ & $16,159(23.3)$ & $19,360(25.4)$ & $21,817(26.9)$ & $22,332(27.3)$ & $25,054(27.9)$ & $27,865(29.6)$ & $\nearrow$ \\
\hline Renal organ failure & $214,785(43.6)$ & $29,032(41.8)$ & $32,334(42.3)$ & $34,910(43)$ & $36,481(44.6)$ & $39,981(44.5)$ & $42,047(44.7)$ & $\nearrow$ \\
\hline Respiratory organ failure & $227,706(46.2)$ & $32,439(46.7)$ & $35,664(46.7)$ & $37,638(46.4)$ & $38,094(46.5)$ & $40,982(45.6)$ & $42,889(45.5)$ & $\searrow$ \\
\hline $\begin{array}{l}\text { Number of organ failure, } \\
\text { median (IQR) }\end{array}$ & $4[3 ; 5]$ & $4[3 ; 5]$ & $4[3 ; 5]$ & $4[3 ; 5]$ & $4[3 ; 5]$ & $4[3 ; 5]$ & $4[3 ; 5]$ & $=$ \\
\hline $\begin{array}{l}\text { SAPS II score, median (IQR) } \\
\quad(\text { miss }=83,156)\end{array}$ & $51[38 ; 67]$ & $51[38 ; 67]$ & $51[38 ; 67]$ & $51[38 ; 67]$ & $51[38 ; 67]$ & $51[38 ; 67]$ & $51[38 ; 68]$ & $\nearrow$ \\
\hline \multicolumn{9}{|l|}{ Outcomes } \\
\hline $\begin{array}{l}\text { Hospital LOS (days) (median } \\
\text { [IQR]) }\end{array}$ & $20[8 ; 39]$ & $20[8 ; 40]$ & $20[8 ; 39]$ & $20[8 ; 39]$ & $20[8 ; 39]$ & $19[8 ; 38]$ & $19[8 ; 37]$ & $\searrow$ \\
\hline $\begin{array}{l}\text { ICU LOS (days) (median [IQR]) } \\
\quad(\text { missing }=133,828)\end{array}$ & $8[3 ; 18]$ & $9[3 ; 20]$ & $9[3 ; 19]$ & $8[3 ; 19]$ & $8[3 ; 18]$ & $8[3 ; 18]$ & $8[3 ; 17]$ & $\searrow$ \\
\hline Discharge to home & $199,613(40.5)$ & $27,067(39)$ & $30,521(40)$ & $32,755(40.4)$ & $32,810(40.1)$ & $37,433(41.6)$ & $39,027(41.4)$ & $\nearrow$ \\
\hline Hospital mortality & $222,709(45.2)$ & $32,091(46.2)$ & $34,967(45.8)$ & $37,007(45.6)$ & $37,146(45.4)$ & $39,872(44.3)$ & $41,626(44.2)$ & $\searrow$ \\
\hline Cost $(€)$, median (IQR) & $\begin{array}{l}16,449 \\
{[7336 ; 29360]}\end{array}$ & $\begin{array}{l}17,261.7 \\
{[7604 ; 30765]}\end{array}$ & $\begin{array}{l}16,129.2 \\
{[6918 ; 29647]}\end{array}$ & $\begin{array}{l}15,886 \\
{[6889 ; 29107]}\end{array}$ & $\begin{array}{l}16,538.6 \\
{[7387 ; 29489]}\end{array}$ & $\begin{array}{l}16,640.1 \\
{[7560 ; 29172]}\end{array}$ & $\begin{array}{l}16,364.6 \\
{[7509 ; 28504]}\end{array}$ & $\searrow$ \\
\hline
\end{tabular}

a Test of trend or linear regression for values from 2010 to $2015 ; \nearrow$ a significant increase is observed with a $p$ value $<0.05$; $\backslash$ a significant decrease is observed with a $p$ value $<0.05 ;{ }^{\prime}=$ ' no significant trend is observed; SAPS II Simplified Acute Physiology Score II; LOS length of stay, ICU intensive care unit 
the decrease although quite smaller was probably more reflective of reality. Our findings could be explained by an improvement in care over time thanks to earlier detection and identification of pathogens, and earlier specific treatment included in care bundles [25, 27]. In contrast, mortality increased in patients not admitted to the ICU regardless of their disease severity. Such results could be explained by pre-mortem misdiagnosis, suboptimal care or early limitation of care. The implicit definition of sepsis using ICD-10 codes included heterogeneous septic patients, almost half of whom were not admitted to the ICU and this could explain why the risk of death was unchanged when all septic patients were considered together.

Finally, we calculated an average cost per hospital stay for septic shock in France of $€ 16,449$ compared to the sum of $€ 17,261$ in 2010 and the current cost of $€ 16,365$. This decrease in costs could have been due to a shorter hospital LOS, mainly because of a shorter ICU LOS, which in turn could be related to the inclusion of older patients with more comorbidities and earlier limitation of care or to earlier discharge of patients to rehabilitation. Another contributing factor could have been an overall improvement in care, with reduction in the time spent on organ support such as ventilation and subsequent reduction in sedation. It is unfortunately difficult to interpret this reduction because of all the confounding factors to be taken into account.

Our work has several strengths. Use of the PMSI allowed all patients with sepsis and septic shock admitted to French hospitals to be included in the study, which with one of the highest number of sepsis and septic shock cases ever recorded gives an accurate picture of the burden they represent for a country with a high standard of care, high hospital bed availability, an integrated healthcare organization structure, and similar admission policies for all patients thanks to its public insurance system. Analysis of a period of time during which diagnostic codes and insurance policies were unchanged ensured that the rise of coding was kept to a minimum. In addition, all procedure codes, diagnostic codes, and the SAPS II scores in the subgroup of ICU patients were taken into account to provide a comprehensive description of septic shock that includes adjustment for mortality risk to a degree not previously attained. We also analyzed hospital stays from admission to death or discharge, taking into account all potential transfers, and adjusting for readmissions, which has not been performed before in similar studies.

Our study has several limitations, mostly related to the nature of the database: the specificity of the coding, the rise in coding due to better recognition and coding, missing data due to billing reasons, and the lack of detailed clinical, paraclinical and drug exposure data. Thus, it was not possible to compare our inclusion criteria with those based on clinical data using the sepsis 3.0 definitions as done elsewhere $[28,29]$ to determine whether our increase was related to coding and to assess the number of misdiagnosed patients. Nor was it possible to differentiate primary infections from nosocomial infections, to know whether limitations of care were achieved or to take into account discharges to a hospice. Finally, our study did not allow causal inferences between sepsis and/ or septic shock and death.

\section{Conclusions}

In conclusion, we showed that sepsis is a common and frequently fatal condition and is associated with high healthcare expenses. In line with other studies based on administrative data, we observed an increased trend in the incidence of sepsis probably due in large part to a better recognition and coding of the infection. We confirmed that improvement in the risk of death for septic shock patients is around $0.3 \%$ per year when case-mix and severity scores are taken into account. Similar results were observed for septic patients admitted to the ICU and those with septicemia, suggesting the benefit of being taken into intensive care. Research on sepsis should be actively undertaken in order to sustain the trend in improved outcomes. Lastly, the decline in mortality rates of septic shock is unclear and warrants further studies.

\section{Supplementary information}

Supplementary information accompanies this paper at https://doi. org/10.1186/s13613-020-00760-x.

Additional file 1. Additional figures and tables.

\section{Abbreviations}

ICU: Intensive care unit; ICD: International Classification of Diseases;; PMSI: Programme de Médicalisation des Systèmes d'Information; SAPS: Simplified Acute Physiology Score; CCAM: Classification Commune des Actes Médicaux; LOS: Length of stay; GHM: Groupe Homogène de Malades; CFR: Case-fatality rates; IQR: Interquartile range.

\section{Acknowledgements \\ We thank Celine Feger from Emibiotech and Jeffrey Watts for her editorial support and Jeffrey Watts.}

\section{Authors' contributions}

$\mathrm{CD}, \mathrm{LB}, \mathrm{JFT}, \mathrm{SB}, \mathrm{SR}, \mathrm{AP}$ designed the study, assisted in data collection and analysis, and drafted and edited the manuscript. DVG, AM, BM, EdM, GP, FS, CV SA, RS assisted in data collection and edited the manuscript. All authors read and approved the final manuscript.

\section{Funding}

The study was partly funded by the Outcomerea study group.

\section{Availability of data and materials}

The datasets used and/or analyzed during the current study are available from the corresponding author upon reasonable request. 


\section{Ethics approval and consent to participate}

In accordance with the French regulatory system regarding personal and medical data and after agreement of the French data protection authority (CNIL), our institution was allowed to access the PMSI database. We only had access to patients diagnosed with sepsis or septic shock according to our definition, and to pseudonymized data.

\section{Consent for publication}

Not applicable.

\section{Competing interests}

We declare that we have no conflicts of interest.

\begin{abstract}
Author details
${ }^{1}$ Medical Intensive Care Unit, Gabriel Montpied University Hospital, Clermont-Ferrand, France. ${ }^{2}$ UMR 1137-IAME Team 5-DeSCID: Decision Sciences in Infectious Diseases control and care INSERM/Univ Paris Diderot, Sorbonne Paris Cité, 75018 Paris, France. ${ }^{3}$ Medical and Infectious Diseases Intensive Care Unit, Bichat Claude Bernard University Hospital, AP-HP, 46 rue Henri Huchard, 75018 Paris, France. ${ }^{4}$ Département D'Informations Médicales, Bichat Claude Bernard University Hospital, AP-HP, 46 rue Henri Huchard, 75018 Paris, France. ${ }^{5}$ Medical Intensive Care Unit, Robert Debré University Hospital, Rue du Général Koenig, 51100 Reims, France. ${ }^{6}$ HP2 Laboratory, INSERM U1042, Univ. Grenoble Alpes, Grenoble, France. ${ }^{7}$ EFCR Laboratory, Grenoble Alpes University Hospital, Grenoble, France. ${ }^{8}$ Department of Anaesthesia and Intensive Care, Bichat Claude Bernard University Hospital, AP-HP, 46 rue Henri Huchard, 75018 Paris, France. ${ }^{9}$ Intensive Care Unit, Centre Hospitalier de La Côte Basque, 64109 Bayonne, France.
\end{abstract}

Received: 24 April 2020 Accepted: 8 October 2020 Published online: 20 October 2020

\section{References}

1. Vincent J-L, Marshall JC, Namendys-Silva SA, FranÇois B, Martin-Loeches I, Lipman J, et al. Assessment of the worldwide burden of critical illness: the Intensive Care Over Nations (ICON) audit. Lancet Respir Med. 2014;2:380-6.

2. Fleischmann C, Scherag A, Adhikari NKJ, Hartog CS, Tsaganos T, Schlattmann $\mathrm{P}$, et al. Assessment of global incidence and mortality of hospitaltreated sepsis. Current Estimates and Limitations. Am J Respir Crit Care Med. 2016;193:259-72.

3. Dellinger RP, Levy MM, Rhodes A, Annane D, Gerlach H, Opal SM, et al. Surviving sepsis campaign: international guidelines for management of severe sepsis and septic shock: 2012. Crit Care Med. 2013:41:580-637.

4. Finfer S, Machado FR. The Global Epidemiology of Sepsis Does It Matter That We Know So Little? Am J Respir Crit Care Med. 2016;193:228-30.

5. Prescott HC, Iwashyna TJ, Blackwood B, Calandra T, Chlan LL, Choong $K$, et al. Understanding and enhancing sepsis survivorship priorities for research and practice. Am J Respir Crit Care Med. 2019;200:972-81.

6. Gaieski DF, Edwards JM, Kallan MJ, Carr BG. Benchmarking the Incidence and Mortality of Severe Sepsis in the United States. Crit Care Med. 2013;41:1167-74.

7. Fleischmann-Struzek C, Mikolajetz A, Schwarzkopf D, Cohen J, Hartog CS, Pletz $\mathrm{M}$, et al. Challenges in assessing the burden of sepsis and understanding the inequalities of sepsis outcomes between National Health Systems: secular trends in sepsis and infection incidence and mortality in Germany. Intensive Care Med. 2018;44:1826-35.

8. Insee Institut national de la statistique et des études économiques. Bilan démographique 2016

9. Dombrovskiy VY, Martin AA, Sunderram J, Paz HL. Rapid increase in hospitalization and mortality rates for severe sepsis in the United States: A trend analysis from 1993 to 2003. Crit Care Med. 2007;35:1244-50.

10. Quan H, Sundararajan V, Halfon P, Fong A, Burnand B, Luthi J-C, et al. Coding algorithms for defining comorbidities in ICD-9-CM and ICD-10 administrative data. Med Care. 2005;43:1130-9.

11. Zhang J, Yu KF. What's the relative risk? A method of correcting the odds ratio in cohort studies of common outcomes. JAMA. 1998;280:1690-1.
12. Angus DC, Linde-Zwirble WT, Lidicker J, Clermont G, Carcillo J, Pinsky MR. Epidemiology of severe sepsis in the United States: analysis of incidence, outcome, and associated costs of care. Crit Care Med. 2001;29:1303-10.

13. Martin GS, Mannino DM, Eaton S, Moss M. The epidemiology of sepsis in the United States from 1979 through 2000. N Engl J Med. 2003;348:1546-54.

14. Kumar G, Kumar N, Taneja A, Kaleekal T, Tarima S, McGinley E, et al. Nationwide trends of severe sepsis in the 21st century (2000-2007). Chest. 2011;140:1223-31.

15. Lagu T, Rothberg MB, Shieh M-S, Pekow PS, Steingrub JS, Lindenauer PK. Hospitalizations, costs, and outcomes of severe sepsis in the United States 2003 to 2007. Crit Care Med. 2012;40:754-61.

16. Bouza C, López-Cuadrado T, Saz-Parkinson Z, Amate-Blanco JM. Epidemiology and recent trends of severe sepsis in Spain: a nationwide population-based analysis (2006-2011). BMC Infect Dis. 2014;14:3863.

17. Stoller J, Halpin L, Weis M, Aplin B, Qu W, Georgescu C, et al. Epidemiology of severe sepsis: 2008-2012. J Crit Care. 2016;31:58-62.

18. Gohil SK, Cao C, Phelan M, Tjoa T, Rhee C, Platt R, et al. Impact of Policies on the Rise in Sepsis Incidence, 2000-2010. Clin Infect Dis. 2016;62:695-703.

19. Elfeky S, Golabi P, Otgonsuren M, Djurkovic S, Schmidt ME, Younossi ZM. The epidemiologic characteristics, temporal trends, predictors of death, and discharge disposition in patients with a diagnosis of sepsis: A crosssectional retrospective cohort study. J Crit Care. 2017;39:48-55.

20. Yébenes JC, Ruiz-Rodriguez JC, Ferrer R, Clèries M, Bosch A, Lorencio $C$, et al. Epidemiology of sepsis in Catalonia: analysis of incidence and outcomes in a European setting. Ann Intensive Care. 2017;7:19.

21. Lee C-C, Yo C-H, Lee MG, Tsai K-C, Lee S-H, Chen Y-S, et al. Adult sepsis - a nationwide study of trends and outcomes in a population of 23 million people. J Infect. 2017;75(5):409-19.

22. Rhee C, Dantes R, Epstein L, Murphy DJ, Seymour CW, Iwashyna TJ, et al. Incidence and Trends of Sepsis in US Hospitals Using Clinical vs Claims Data, 2009-2014. JAMA. 2017;318:1241.

23. Dellinger RP, Levy MM, Carlet JM, Bion J, Parker MM, Jaeschke R, et al. Surviving Sepsis Campaign: International guidelines for management of severe sepsis and septic shock: 2008. Intensive Care Med. 2008;34:17-60.

24. Kadri SS, Rhee C, Strich JR, Morales MK, Hohmann S, Menchaca J, et al. Estimating Ten-Year Trends in Septic Shock Incidence and Mortality in United States Academic Medical Centers Using Clinical Data. Chest. 2017;151:278-85

25. Rhee C, Murphy MV, Li L, Platt R, Klompas M, for the Centers for Disease Control and Prevention Epicenters Program. Comparison of Trends in Sepsis Incidence and Coding Using Administrative Claims Versus Objective Clinical Data. Clin Infect Dis. 2015;60:88-95.

26. Shankar-Hari M, Harrison DA, Rowan KM. Differences in impact of definitional elements on mortality precludes international comparisons of sepsis epidemiology - a cohort study illustrating the need for standardized reporting. Crit Care Med. 2016;44:2223-30.

27. Ferrer R, Artigas A, Levy MM, Blanco J, González-Díaz G, GarnachoMontero J, et al. Improvement in process of care and outcome after a multicenter severe sepsis educational program in Spain. JAMA. 2008;299:2294-303.

28. Rhee C, Jentzsch MS, Kadri SS, Seymour CW, Angus DC, Murphy DJ, et al. Variation in identifying sepsis and organ dysfunction using administrative versus electronic clinical data and impact on hospital outcome comparisons. Crit Care Med. 2019;47:493-500.

29. Jolley RJ, Sawka KJ, Yergens DW, Quan H, Jetté N, Doig CJ. Validity of administrative data in recording sepsis: a systematic review. Crit Care. 2015;19:139.

\section{Publisher's Note}

Springer Nature remains neutral with regard to jurisdictional claims in published maps and institutional affiliations. 